\title{
Risk and Responsibility: A Complex and Evolving Relationship
}

\author{
Céline Kermisch
}

Received: 28 June 2010/Accepted: 2 November 2010/Published online: 20 November 2010

(C) Springer Science+Business Media B.V. 2010

\begin{abstract}
This paper analyses the nature of the relationship between risk and responsibility. Since neither the concept of risk nor the concept of responsibility has an unequivocal definition, it is obvious that there is no single interpretation of their relationship. After introducing the different meanings of responsibility used in this paper, we analyse four conceptions of risk. This allows us to make their link with responsibility explicit and to determine if a shift in the connection between risk and responsibility can be outlined. (1) In the engineer's paradigm, the quantitative conception of risk does not include any concept of responsibility. Their relationship is indirect, the locus of responsibility being risk management. (2) In Mary Douglas' cultural theory, risks are constructed through the responsibilities they engage. (3) Rayner and (4) Wolff go further by integrating forms of responsibility in the definition of risk itself. Analysis of these four frameworks shows that the concepts of risk and responsibility are increasingly intertwined. This tendency is reinforced by increasing public awareness and a call for the integration of a moral dimension in risk management. Therefore, we suggest that a form of virtue-responsibility should also be integrated in the concept of risk.
\end{abstract}

Keywords Risk - Responsibility $\cdot$ Models of risk $\cdot$ Cultural theory $\cdot$ Virtue

\section{Introduction}

With the development of new technologies and their associated risks, the questions of risk and responsibility have found a major place in ethical debates. These issues emerged with the introduction of nuclear technologies and are now exacerbated by

C. Kermisch $(\bowtie)$

Fonds de la Recherche Scientifique, Centre de Recherches Interdisciplinaires en Bioéthique (CP175/01), Université Libre de Bruxelles, 50 av. F. D. Roosevelt, 1050 Bruxelles, Belgium e-mail: ckermisc@ulb.ac.be 
emerging technologies such as bio- or nanotechnologies, which involve not only calculable risks but also "unknown" risks i.e. uncertainty and ignorance in the sense of Stirling (1998). As Anthony Giddens puts it, in "a world dominated by manufactured rather than external uncertainty, there is a renewed discussion of the nature of responsibility"; there is a "crisis of responsibility, because the connections between risk, responsibility and decisions alter" (Giddens 1999, pp. 7-8). This crisis requires us more than ever to study the link between the concepts of risk and responsibility. Quite surprisingly in this context, even if much attention has been paid to the notions of risk and responsibility, the link between these two concepts has not often been analyzed. ${ }^{1}$

At first glance, this link might seem obvious: someone needs to be held responsible-in fact, liable-for a risk when it "materializes", that is, in case some damage occurs. However, if we take a closer look, the picture is much more complex, both from an empirical and a theoretical perspective. The purpose of this paper is to analyse, at the conceptual level, how these two evidently political and controversial notions are related.

Since neither risk nor responsibility has an unequivocal definition, it is obvious that there is no single interpretation of their relationship. In order to analyse the nature of their link, four conceptions of risk will be analyzed. This will allow us to clarify their link with responsibility and to determine if a shift in the connection between risk and responsibility can be outlined.

The paper is structured as follows. First, we will briefly review the conceptions of responsibility that will be used in the paper. Then we will consider the notion of risk as defined technically in the standard engineer's paradigm. Next we will consider an anthropological standpoint, through the analysis of Mary Douglas' research about risk as a cultural process. Afterwards we will introduce the models of two authors who integrate different notions of responsibility in the concept of risk itself: Rayner's polythetic concept of risk and Wolff's multi-level model of risk. A discussion section will follow, where the different conceptions will be analyzed and compared.

\section{Conceptions of Responsibility}

Before introducing the various conceptions of risk, it is useful to review the different meanings of responsibility that will be referred to in this paper: roleresponsibility, causal-responsibility, liability-responsibility, capacity-responsibility, blame and virtue-responsibility.

Distinctions between role-responsibility, causal-responsibility, liability-responsibility and capacity-responsibility have been established by Herbert Hart (2008, pp. 212-222). These can be briefly defined as follows.

Role-responsibility is linked to a specific position to which particular duties are attached. For example, a pilot is responsible for the flight of his aircraft, or parents

\footnotetext{
1 At least not at the theoretical level. However there are several exceptions, for example the works of Hans Lenk. See amongst others (Lenk and Maring 2001) or (Lenk 2007).
} 
are responsible for the welfare of their children and are thus responsible for not leaving them alone in a car. ${ }^{2}$

Causal-responsibility refers to the cause, understood in a quasi-mechanical sense, of an event. The storm is responsible for the plane crash, or the heat is responsible for the death of the baby left alone in a car.

Capacity-responsibility refers to the capacity of an agent to fulfil his responsibilities. Being responsible for his/her own actions implies having the capacity of understanding, reasoning and controlling the conduct. If the pilot has a heart attack, he is not responsible for the plane crash.

Liability-responsibility is the legal facet of responsibility. It is a retrospective form of responsibility that answers the questions of who will have to be punished, who will have to explain the unwanted event, and/or who will have to pay compensation for the damages. If someone has a car accident because he/she is driving while drunk, he/she is liable to pay for the damages.

Besides these meanings of responsibility introduced by Hart, the paper will also refer to blame insofar as the notion of responsibility is sometimes used in the meaning of blameworthiness. Blame occurs when there is violation of a moral norm and when someone's behaviour is morally culpable (Wolff 2006, pp. 418-419). It implies (1) that the agent has capacity-responsibility, (2) that he/she has done something wrong and (3) that he/she is causally responsible for the harmful event (Johnson 2005, p. 1617). For example, blame is at stake when someone has committed an act of sabotage or of terrorism.

Finally, virtue-responsibility is used in the sense of moral responsibility developed by John Ladd, as a form of responsibility which refers to moral deficiency and not just to fault (Ladd 1991, pp. 85-89) - for example, the absence of care or concern for the welfare of others. Responsibility is here a question of relationship, where the agent does something that affects someone else. This relationship describes "how things are and how things should be or should have been" (Ladd 1991, p. 86). It is thus both descriptive and normative, and both prospective and retrospective. Ladd illustrates this notion of virtue-responsibility with the case of the Bhopal accident: even if no one was really at fault, safety was not a priority of the management. This situation expresses an absence of care for people at risk, which has to be understood as an absence of virtue-responsibility.

\section{Risk and Responsibility in the Engineer's Paradigm}

In technical risk analysis, risk is most commonly defined as the statistical expectation value of unwanted events, which may or may not occur (Hansson 2004, p. 10). For instance the European Commission's report dedicated to the harmonisation of risk assessment procedures suggests that "risk is widely recognized as a function of the probability and severity of an adverse effect/event occurring to man

\footnotetext{
2 This is the meaning which is used in this paper even though Hart uses also the notion of role-responsibility for qualifying someone as responsible when he/she takes his/her duties seriously (a "responsible person").
} 
or the environment following exposure, under defined conditions, to a hazard" (European Commission 2000, p. 18). In the same view, the National Research Council, on the one hand, defines hazard as "an act or phenomenon posing potential harm to some person(s) or thing(s); the magnitude of the hazard is the amount of harm that might result, including the seriousness and the number of people exposed" and, on the other hand, it defines risk as a concept adding "to the hazard and its magnitude the probability that the potential harm or undesirable consequences will be realized" (National Research Council 1989, p. 321). In other words, risk corresponds to "the combined answers to (1) What can go wrong? (2) How likely is it? (3) What are the consequences?" (National Research Council 2009). This conception was also the one adopted in the seventies by engineers such as Chauncey Starr or William Lowrance, pioneers in systematizing risk acceptability rules (Starr et al. 1976, pp. 640-664; Lowrance 1976, p. 8).

These definitions used in risk analysis reveal clearly a consensus about the "essence" of risk, which refers to a mode of representation of events explicitly based on probabilities. This standpoint assumes a reified conception of risk, considered as a characteristic of the risky technology and excluding the perceiving subject.

At first glance, the link between this strictly quantitative conception of risk and the notion of responsibility may seem tenuous. Indeed, as many philosophers have pointed out, this definition of risk is totally disconnected from the risk actors-see for example (Bourg and Schlegel 2001, pp. 37-38) — and is thus also disconnected from the allocation of responsibilities. Hence the concept of risk used in the engineer's paradigm does not inherently integrate any notion of responsibility.

However, even if the notions of risk and responsibility are conceptually distinct in this framework, we cannot say that they are mutually exclusive. Indeed, they do relate to each other in the risk management process. More precisely, according to the engineer's paradigm, the traditional risk management scheme distinguishes in principle two phases: risk assessment and risk management in itself (Lowrance 1976, p. 8 and pp. 75-76). The first is supposed to deal with questions of "facts"; it consists in the identification and the quantification of risk. The second, on the other hand, concerns the acceptability of risk and its societal management. Thus it involves questions of "values". 3 The risk assessment phase does not leave any room for questions of responsibility of any type, which are transferred to the risk management stage where several notions of responsibility are strongly embedded. When an unwanted event has occurred, liability-responsibility is at stake: the focus is on trying to find out who has to "pay" for the damages. As liability-responsibility implies capacity-responsibility and causal-responsibility as preconditions, both of these are thus indirectly at stake here too (Van de Poel 2010). Role-responsibility is also invoked in case an unwanted event occurs insofar as attention is paid to the way the different individuals involved in the accident have or have not fulfilled their duties.

\footnotetext{
3 The separation between risk assessment and management has often been challenged for several reasons, as well as the fact/value dichotomy. See for example (Shrader-Frechette 1991, pp. 39-46) or (Silbergeld 1991).
} 
In the engineer's paradigm, it thus appears that the link between the concept of risk and the notion of responsibility is only indirect, the locus of responsibility being risk management.

\section{Risk Selection and Responsibility Allocation in Cultural Theory}

In the eighties, the British anthropologist Mary Douglas drastically renewed the way risk and responsibility are conceived. Indeed, in her very controversial book, Risk and Culture-written with Aaron Wildavsky-, Douglas applies cultural theory to the question of risk in modern societies, introducing thereby a constructed concept of risk (Douglas and Wildavsky 1982).

As a reminder, cultural theory was developed by the anthropologist through the study of primitive societies. Its basic hypothesis states that cultural biases and social organizations mutually maintain each other. ${ }^{4}$ To put it in another way, each cultural bias performs a function of stabilization of the corresponding social organization, which is typical of the functionalist tradition in sociology. In Cultural bias, Mary Douglas defines four types of social organizations: the hierarchical, the insulated, the individualistic and the egalitarian forms (Douglas 1979). ${ }^{5}$ Each social organization-or social form-can be characterized specifically. In hierarchical forms, the social roles are clearly specified and the related distribution of resources is often inequitable. In insulated forms, individuals do not have the possibility to make personal transactions, their autonomy is minimal and their social roles are completely determined by the individuals of other social forms. These insulated individuals undergo their life passively; therefore they are sometimes called "fatalists". In the case of individualistic forms, the conditions are strongly competitive and individual autonomy is important. Finally, in egalitarian forms, the roles are not defined and the fundamental social constraints are related to the protection, by the group, of the outside border against foreigners ("outsiders") and to the control exercised in the name of the group over the behaviour of individuals.

As each social organization is maintained by a cultural bias covering the whole cognitive and axiological content, it is also sustained by a particular set of risks (Douglas and Wildavsky 1982). More precisely, "the question is not which dangers are most alarming but which explanations of misfortune are likely to function most effectively" in the different kinds of social organizations, that is which explanations of misfortune are the most effective in maintaining the social organization (Douglas 1985 , p. 59). It is thus not surprising that the risks that are focused on vary from one social organization to another. In hierarchical forms, the prevailing shared fear is the

\footnotetext{
4 The concept of cultural bias designates here the beliefs, the values, as well as the ways to perceive the world and to react to it. On the other hand, the notion of social organization deals only with the interpersonal relationship patterns. It designates a group or a network of individuals, who share the same social characteristics, and not a society as a whole.

5 The four types of social organizations are constructed according two dimensions, group and grid. Group represents the level of social incorporation of the individual in a social unit while grid integrates the institutionalized classifications, which regulate the interactions of members of any social structure.
} 
collapse of the system; the risks on which individuals focus are those that threaten it, such as riots and wars. ${ }^{6}$ In insulated forms, the individuals do not have-by definition-the possibility to manage their own life and thus they are not able to manage the risks they face. Therefore they do not care about risks. In individualistic forms, the risk that is emphasized is the collapse of the market. Finally, the risks highlighted in egalitarian forms are those that conflict with their demand for purity, such as environmental pollution or technological risks, both seen as external threats.

Cultural theory considers that each cultural bias has a propensity to focus on a particular type of danger - among the multiple surrounding dangers - and to neglect others. In other words, each cultural bias selects the dangers that contribute to the stabilization of the corresponding social organization, thereby "translating" these into risks. Risks are thus constructed according to a social process in which individuals are involved as active subjects: a risk does not only characterise an element of the external world - a danger-but results from the interaction between social processes and, possibly, the external world.

In a later book, Risk according to social sciences, Mary Douglas further analyzes the process of risk selection, revealing a link between risk selection and responsibility allocation (Douglas 1985). Hence she investigates the procedures of responsibility and blame allocation.

From a functionalist perspective, these procedures vary according to the type of social organization. More specifically, in insulated forms, individuals do not seek to allocate responsibility or blame. Indeed, as they do not care about risks, they do not need to find someone to blame or to hold responsible in case an accident occurs. On the other hand, hierarchies tend to blame the victims or their relatives in order to assure internal social control. Egalitarian societies concentrate rather on "outsiders" in order to increase the loyalty to the group. In both of these cases, the focus is on the reinforcement of the social cohesion. In individualist organizations, the logic of individual competition tends to attribute one's own misfortune to luckier or more talented rivals. Therefore, individuals are claiming responsibilities rather than blaming others for what happened, which is another way to maintain the system (Douglas 1985, pp. 62-63).

Public allocation of blame and responsibility contributes thus to the stabilization of social organizations. According to Douglas, this allocation is associated with the advertising of certain kinds of risks (Douglas 1985, p. 56). To put it in another way, the cultural processes that lead to a focus on certain kinds of dangers corresponds to the cultural processes that allocate blame and responsibility (Douglas 1985, p. 53 and 72). Responsibility and blame play thus a role as important as risk in this functionalist framework.

The link between risk and responsibility in Douglas' cultural theory is thus established in a more direct way compared with the engineer's paradigm: in this case, these concepts are inseparable insofar as the notion of risk is constructed through the cultural processes of responsibility and blame allocation.

\footnotetext{
6 To understand how Douglas establishes which risks are focused on in each social organization, see (Douglas and Wildavsky 1982).
} 


\section{Introducing a Polythetic Definition of Risk Including the Notion of Liability}

In the late eighties, Steve Rayner, whose works were heavily influenced by cultural theory, explicitly rejected the quantitative definition of risk typical of the engineers' paradigm. He criticizes its essentialist character, which implies that, as soon as there is an agreement on which consequences are unwanted, the factors of probability and magnitude are necessary and sufficient conditions for stating that something is defined as a risk and for determining it. Thereby other factors that might be relevant are considered as being only "by-products" instead of inherent parts of risk. It is in this perspective that Rayner proposes to rethink the epistemological status of risk, trying to determine which type of definition would be the most appropriate (Rayner and Cantor 1987, pp. 3-5; Rayner 1987, pp. 208-210).

With this goal in mind, Rayner refers to the notion of "open concept", introduced by Wittgenstein in his Philosophical investigations (Wittgenstein, 1953). As a reminder, Wittgenstein exemplifies this kind of concept through the notion of game: the concept of game cannot be caught by an essentialist definition, as it is impossible to find particular characteristics that would be common to all games. Therefore he proposes to consider the concept of game as an open-or polythetic-concept. It consists in considering the concept as a chain of elements, which do not need to have common characteristics from the one end of the chain to the other. Rather they need only to present some similarities. ${ }^{7}$ It is as a polythetic concept that Rayner conceptualizes technological risk, the different standpoints-experts' from different disciplines and lay people's - constituting the links of the conceptual chain.

More specifically, Rayner suggests that, when dealing with risk, lay people are giving more importance to the notions of trust, liability and consent (Rayner 1992, pp. 94-96). This leads him to formulate a new definition of risk:

$$
\mathrm{R}=(\mathrm{P} \times \mathrm{M})+(\mathrm{T} \times \mathrm{L} \times \mathrm{C})
$$

where $\mathrm{P}=$ probability of occurrence of the adverse event; $\mathrm{M}=$ magnitude of the adverse consequences; $\mathrm{T}=$ trust put in the institutions regulating the technology; $\mathrm{L}=$ acceptability of the principle used to apportion liabilities; $\mathrm{C}=$ acceptability of the procedure by which collective consent is obtained.

The first term of this definition $(\mathrm{P} \times \mathrm{M})$, corresponds to the "scientific end" of the conceptual chain, and the second term $(\mathrm{T} \times \mathrm{L} \times \mathrm{C})$, to its "societal end" - the principles of trust, liability and consent may vary according to the cultural context. ${ }^{8}$

Far from being as univocal as risk in the engineer's paradigm, the model proposed by Rayner explicitly integrates in the definition of risk itself moral and political dimensions such as trust, consent, but also liability.

\footnotetext{
${ }^{7}$ For example, there are no common characteristics between football, cricket, chess or solitaire, but there are some similarities. Indeed, cricket and football are two games where two teams are facing each other with a ball on a ground, but their rules differ. Their common denominator with chess is their competitive characteristic, which is irrelevant in the case of solitaire. On the other hand, chess and solitaire both consist in moving pieces on a board, and so on.

${ }^{8}$ Paradoxically, even if Rayner explicitly rejects the technical definition of risk for its essentialist character, grasping the concept of risk with this formula seems nevertheless to presuppose some essentialist notion.
} 


\section{The Anatomy of Risk According to Wolff}

In 2006, Jonathan Wolff observes the limitations of quantified risk assessment, which he considers to be inadequate for capturing all societal concerns (Wolff 2006). As well as Rayner, he considers the definition of risk used in the engineer's paradigm as insufficient. Indeed, probabilities and hazards are unsatisfactory for an effective risk analysis insofar as two hazards with the same magnitude are not necessarily equal: one can be worse than another because it generates greater fear or moral concern, for example (Wolff 2006, p. 418). It is in this perspective that Wolff constructs a new model of risk called the "anatomy of risk". Besides probability and magnitude, it integrates several other factors in the definition of risk itself: cause, fear and moral concern.

Wolff considers first the cause of the hazard, i.e. "the process by which the hazard comes into being, or is sustained, or perhaps, permitted" (Wolff 2006, p. 418). Implicitly, he refers thus to a causal conception of responsibility.

Wolff also observes that safety policies take into account subjective risks rather than quantified "objective" risks. Safety policy implicitly gives the priority to the reduction of fear rather than to the reduction of quantified risk. The role of fear in the setting of safety policies appears thus to be undeniable.

However, when judging risks, moral concern appears to play an even greater role than fear. People tend to focus on "morally blameworthy behaviours" and to reject them. These behaviours can be classified in four categories: malice, recklessness, negligence and incompetence. "Malice is to set out a course of action with the deliberate aim of imposing harm or risks to people. Recklessness is to act knowing that it could cause harm or risk, but not taking this properly into account in deciding whether to act. Negligence is to fail to consider whether or not your action carries risks to others, when such risks were reasonably foreseeable. Incompetence, in this context, is to carry out a proper risk assessment and decide to take appropriate action, but fail to do so" (Wolff 2006 pp. 418-419). When blaming people who behave with malice, recklessness, negligence or incompetence, several forms of responsibility are indirectly at stake insofar as blame implies capacity-responsibility, causal-responsibility, as well as the fact that the agent has done something wrong - which might in turn be linked to role-responsibility and/or liabilityresponsibility. As in the case of fear, blame drastically influences people's attitudes towards risks.

Another moral reaction consists in the shame individuals might feel when they identify themselves with the actors at the origin of an adverse event or when they feel partly responsible for the event (Wolff 2006, p. 425).

The originality of the model introduced by Wolff lies in its multi-level variables: he distinguishes primary variables - probability, hazard and cause-from secondary variables - fear, blame and shame-, which are taking the primary ones as objects. Fear is attached to hazard and probability whereas blame and shame are associated with cause, hazard, or probability. If shame and blame are not at stake, the introduction of cause as a primary variable appears to be useless and the technical definition of risk is valid. Wolff is conscious of the fact that more secondary variables-and maybe even tertiary variables (such as regret that something is the 
cause of shame)—should probably be included in his model (Wolff 2006, p. 425). However, he does not investigate this lead further.

As Rayner, Wolff systematically takes into account, in his conception of risk, a certain number of sociocultural values, which refer to the concept of responsibility, mainly through the introduction of the notions of cause, blame and-to a lesser degree-shame. ${ }^{9}$

\section{Discussion}

If we accept, with Paul Thompson, a contextual conception of risk (Thompson and Dean 1996), we have to admit that risk may include a value-laden component as well as a quantitative component. In this perspective, Douglas', Rayner's and Wolff's conceptions of risk are more relevant than the quantitative conception of risk used in the engineer's paradigm, which is not conceptually connected to social values, and hence not to the notion of responsibility.

Douglas' conceptions of risk and responsibility appear to be attractive and original. She clearly has been a pioneer in moving the concepts of risk and responsibility forward. Indeed she is the first author to link these concepts: adopting a culturalist/functionalist perspective, she considers that, in order to maintain social coherence, risks are constructed through the responsibilities and the blames they engage. This leads to the question of determining if a "risk", which does not imply responsibility or blame, is still considered as a "risk" by Douglas. Implicitly, her answer is negative. Indeed, because it does not play any stabilizing role, it is not selected as a "risk" anymore-in Douglas' sense-but it is considered as a danger. The relationship between risk and responsibility is thus much stronger in Douglas' theory than in the engineer's paradigm, even though the connection between these two notions is still indirect and unclear.

We can criticize Douglas for the confused nature of her text, which includes many extrapolations, notably when she describes how the procedures of blame and responsibility allocation work. Another criticism of Douglas' view of risk in relationship to responsibility comes from the fact that the culturalist framework appears to be too rigid. With the variety of risk and responsibility problems that are nowadays at stake, it is difficult to support the idea that there are only three different ways - according to the three main cultural biases-to conceptualize these notions and their links. Finally, Douglas only focuses on two particular types of responsibility-blame and moral responsibility-which is a choice that can be questioned. She could indeed have enlarged her analysis to other dimensions of responsibility such as liability.

Steve Rayner's model is the first one which attempts to formalize the link between risk and responsibility: Rayner integrates the notion of liability in the definition of risk itself, through the formula: $\mathrm{R}=(\mathrm{P} \times \mathrm{M})+(\mathrm{T} \times \mathrm{L} \times \mathrm{C})$.

\footnotetext{
9 The importance attached to the notion of blame inevitably brings us back to Douglas' works. However, here the notion of blame does not play a functionalist role. Rather it refers to ethical and political values, in a framework focused on citizens' demands.
} 
However, this conception of risk raises several problems. First, we might ask how to empirically quantify the $\mathrm{T}, \mathrm{L}$ and $\mathrm{C}$ components and in which units to express these. ${ }^{10}$ Moreover, we can assume that the units of the different variables in this formula are heterogeneous. This raises the question of how the variables should be combined. Further analysis would be required to solve this problem. In the meantime, stating that risk is a function of these five variables would be more cautious: $\mathrm{R}=\mathrm{f}(\mathrm{P}, \mathrm{M}, \mathrm{T}, \mathrm{L}, \mathrm{C})$.

Wolff offers another perspective. Indeed, we have seen how Wolff introduces several notions linked to the concept of responsibility-cause, blame and shame-in his model of risk. His conception of risk might be formalized as $\mathrm{R}=\mathrm{f}(\mathrm{P}, \mathrm{H}, \mathrm{C}, \mathrm{F}$, $\mathrm{B}, \mathrm{S} \ldots$ ), where $\mathrm{P}=$ probability, $\mathrm{H}=$ hazard, $\mathrm{C}=$ cause, $\mathrm{F}=$ fear, $\mathrm{B}=$ blame, and $\mathrm{S}=$ shame. More precisely, $\mathrm{R}=\mathrm{f}(\mathrm{F}, \mathrm{B}, \mathrm{S})$, with $\mathrm{F}=\mathrm{f}(\mathrm{P}, \mathrm{H}), \mathrm{B}=\mathrm{f}(\mathrm{P}, \mathrm{H}, \mathrm{C})$, and $\mathrm{S}=\mathrm{f}(\mathrm{P}, \mathrm{H}, \mathrm{C})$. As in the conception of risk elaborated by Rayner, the notions of risk and responsibility are here inherently intertwined.

The successive introduction of these four models illustrates a clear will to associate the notions of risk and responsibility more systematically. In fact, this development can be understood in a broader perspective: the focus on responsibility reflects more generally the citizens' demand for integration of some moral dimension into risk management, which arises from the multiple recent scandalsfor example the asbestos scandal, the BSE epidemic, or, more recently, the financial crisis or the environmental disaster in the Gulf of Mexico caused by the BP oil spill-and from the resulting loss of trust in decision makers and experts.

With the recent focus on the need to preserve the environment and with the development of emerging technologies such as bio- or nanotechnologies, an increasingly greater part of the public is not only expecting that scientists and decision-makers behave responsibly in their choices-responsibly understood in a retrospective way. The public are also demanding that experts and decision-makers behave in a responsible way, understood in a moral and prospective sense: an attitude of care for others is at the centre of their expectations. Therefore, we suggest that the integration in the concept of risk of the retrospective forms of responsibility proposed by Rayner-liability-responsibility-and Wolff-cause, blame and shame-is insufficient. Another form of responsibility should also be introduced as a dimension of the concept of risk, that is, John Ladd's virtueresponsibility defined in section "Conceptions of responsibility" (Ladd 1991).

Of course, this suggestion does not solve the more general problems of the determination of the factors that have to be included in the concept of risk and how these have to be combined. Indeed, besides Rayner and Wolff, many authors have advocated other conceptions of risk, where different values are at stake. For example, Hansson stresses aspects such as equity, rights, intention, etc. (Hansson 2005 , p. 1097). However, the discussion about which dimensions to take into account falls beyond the scope of this paper. Therefore, we advocate a concept of risk which is formalized as $R=\mathrm{f}\left(X_{1}, X_{2}, \ldots X_{n}\right)$, where $X_{\mathrm{i}}$ are the different variables that have to be considered and $n$ is the number of these variables. Among these

\footnotetext{
${ }^{10}$ Steve Rayner does not specify how T, L and C have to be taken into account. We suppose T, L and C are defined as the inverse of the respective acceptabilities and trust.
} 
variables, Rayner and Wolff have shown that several meanings of retrospective responsibility have to be included. To these, we add the notion of virtueresponsibility, which is both retrospective and prospective.

\section{Conclusion}

Even if the technical conception of risk used in the engineer's paradigm remains operational and powerful at the risk quantification stage, the introduction of new conceptions of risk indicates that risk and responsibility are increasingly connected. This paper suggests that several forms of responsibility should be integrated in the concept of risk, that is, liability-responsibility, causal-responsibility, blame, shame, capacity-responsibility, role-responsibility as well as virtue-responsibility.

Over the years, the understanding of this field has improved but has also become more complex. There are two ways to progress our knowledge. The first would be to work on new dimensions to be integrated into the concept of risk. The second would take as a base forms of responsibility connected to the concept of risk discussed above and would work out how these notions are linked together and how they can practically be applied. This would allow consolidating existing knowledge in order to improve understanding and efficiency in this field.

Acknowledgments The work presented in this paper has been supported by a postdoctoral grant from the Fonds de la Recherche Scientifique (FNRS, Belgium). The author wishes to express special thanks to Ibo Van de Poel for his helpful suggestions on an earlier draft of this paper. She is also very grateful to the two reviewers whose comments clearly have contributed to improve the paper.

\section{References}

Bourg, D., \& Schlegel, J. L. (2001). Parer aux risques de demain. Paris: Le Seuil.

Douglas, M. (1979). Cultural bias. London: Royal Anthropological Institute (Occasional paper No. 35).

Douglas, M. (1985). Risk acceptability according to the social sciences. London: Routledge and Kegan Paul.

Douglas, M., \& Wildavsky, A. (1982). Risk and culture. Berkeley: University of California Press.

European Commission. (2000). First report on the harmonisation of risk assessment procedures. http://ec.europa.eu.

Giddens, A. (1999). Risk and responsibility. The modern law review, 62(1), 1-10.

Hansson, S. (2004). Philosophical perspectives on risk. Techné, 8(1), 10-35.

Hansson, S. (2005). Risk ethics. In C. Mitcham (Ed.), Encyclopedia of science, technology, and ethics (pp. 1642-1645). Farmington Hills: Thompson Gale.

Hart, H. (2008, 1968 for the first edition). Punishment and responsibility: Essays in the philosophy of law. New York: Oxford University Press.

Johnson, D. (2005). Responsibility. Anglo-American perspectives. In C. Mitcham (Ed.), Encyclopedia of science, technology, and ethics (pp. 1616-1618). Farmington Hills: Thompson Gale.

Ladd, J. (1991). Bhopal: An essay on moral responsibility and civic virtue. Journal of Social Philosophy, 22(1), 73-91.

Lenk, H. (2007). A propos de risque et de responsabilité. In C. Kermisch \& G. Hottois (Eds.), Techniques et philosophies des risques (pp. 21-56). Paris: Vrin.

Lenk, H., \& Maring, M. (2001). Responsibility and technology. In A. Auhagen \& H. Bierhoff (Eds.), Responsibility: The many faces of a social phenomenon. London: Routledge.

Lowrance, W. (1976). Of acceptable risk. Los Altos: Kaufmann. 
National Research Council. (1989). Improving risk communication. Washington: National Academy Press.

National Research Council. (2009). Risk. http://www.nrc.gov/reading-rm/basic-ref/glossary/risk.html.

Rayner, S. (1987). Learning from the blind men and the elephant, or seeing things whole in risk management. In V. Covello, et al. (Eds.), Uncertainty in risk assessment, risk management and decision making (pp. 207-212). New York: Plenum Press.

Rayner, S. (1992). Cultural theory and risk analysis. In S. Krimsky \& D. Golding (Eds.), Social theories of risk (pp. 83-115). Westport: Praeger.

Rayner, S., \& Cantor, R. (1987). How fair is safe enough? Risk Analysis, 7(1), 3-9.

Shrader-Frechette, K. (1991). Risk and rationality. Berkeley and Los Angeles: University of California Press.

Silbergeld, E. (1991). Risk assessment and risk management: An uneasy divorce. In D. Mayo \& R. Hollander (Eds.), Acceptable evidence (pp. 9-28). New York \& Oxford: Oxford University Press.

Starr, C., Rudman, R., \& Whipple, C. (1976). Philosophical basis for risk analysis. Annual Review of Energy, 1, 629-662.

Stirling, A. (1998). Risk at a turning point? Journal of Risk Research, 1(2), 97-109.

Thompson, P., \& Dean, W. (1996). Competing conceptions of risk. Risk: Environment, Health, and Safety, 7, 361-384.

Van de Poel, I. (2010). The relation between forward-looking \& backward-looking responsibility. In: N. Vincent, I. Van de Poel \& J. Van den Hoven (Eds.), Moral responsibility. Beyond free will and determinism. Dordrecht: Springer (forthcoming).

Wittgenstein, L. (1953). Philosophical investigations. Oxford: Blackwell.

Wolff, J. (2006). Risk, fear, blame, shame and the regulation of public safety. Economics and Philosophy, 22, 409-427. 